\title{
Thermodynamics in cancers: opposing interactions between PPAR gamma and the canonical WNT/beta-catenin pathway
}

\author{
Yves Lecarpentier ${ }^{*}$ (D), Victor Claes $^{2}$, Alexandre Vallée ${ }^{3}$ and Jean-Louis Hébert ${ }^{4}$
}

\begin{abstract}
Cancer cells are the site of numerous metabolic and thermodynamic abnormalities. We focus this review on the interactions between the canonical WNT/beta-catenin pathway and peroxisome proliferator-activated receptor gamma (PPAR gamma) in cancers and their implications from an energetic and metabolic point of view. In numerous tissues, PPAR gamma activation induces inhibition of beta-catenin pathway, while the activation of the canonical WNT/ beta-catenin pathway inactivates PPAR gamma. In most cancers but not all, PPAR gamma is downregulated while the WNT/beta-catenin pathway is upregulated. In cancer cells, upregulation of the WNT/beta-catenin signaling induces dramatic changes in key metabolic enzymes that modify their thermodynamic behavior. This leads to activation of pyruvate dehydrogenase kinase1 (PDK-1) and monocarboxylate lactate transporter. Consequently, phosphorylation of PDK-1 inhibits the pyruvate dehydrogenase complex (PDH). Thus, a large part of pyruvate cannot be converted into acetyl-coenzyme A (acetyl-CoA) in mitochondria and only a part of acetyl-CoA can enter the tricarboxylic acid cycle. This leads to aerobic glycolysis in spite of the availability of oxygen. This phenomenon is referred to as the Warburg effect. Cytoplasmic pyruvate is converted into lactate. The WNT/beta-catenin pathway induces the transcription of genes involved in cell proliferation, i.e., MYC and CYCLIN D1. This ultimately promotes the nucleotide, protein and lipid synthesis necessary for cell growth and multiplication. In cancer, activation of the PI3K-AKT pathway induces an increase of the aerobic glycolysis. Moreover, prostaglandin E2 by activating the canonical WNT pathway plays also a role in cancer. In addition in many cancer cells, PPAR gamma is downregulated. Moreover, PPAR gamma contributes to regulate some key circadian genes. In cancers, abnormalities in the regulation of circadian rhythms (CRs) are observed. CRs are dissipative structures which play a key-role in far-from-equilibrium thermodynamics. In cancers, metabolism, thermodynamics and CRs are intimately interrelated.
\end{abstract}

Keywords: PPAR gamma, WNT/beta-catenin, Cancer, Circadian rhythms, Pyruvate dehydrogenase kinase, Pyruvate dehydrogenase complex, Aerobic glycolysis, Warburg effect, PI3 K-AKT pathway, Dissipative structures

\section{Introduction}

Schrödinger in his famous book "What is life" [1] provided us a new understanding of the thermodynamics in living systems. By applying this to the thermodynamics of physical, chemical and biological far-from-equilibrium systems, Prigogine and his colleagues opened new avenues for the exploration of dissipative structures

\footnotetext{
*Correspondence: yves.c.lecarpentier@gmail.com

${ }^{1}$ Centre de Recherche Clinique, Hôpital de Meaux, 6-8 rue Saint Fiacre, 77100 Meaux, France

Full list of author information is available at the end of the article
}

which occupy a major place in the living world [2, 3]. Cancer is an exergonic process in which heat flows from the tumor to its surroundings [4]. The entropy production rate is increased in cancer cells and is characteristic of irreversible processes driven by changes in heat production, Gibbs energy, intracellular acidity, ionic conductance, membrane potential gradient [5]. Numerous cellular mechanisms can induce and develop carcinogenic processes. In most cancers, the $\mathrm{WNT} /$ beta-catenin pathway is upregulated while peroxisome proliferatoractivated receptor gamma (PPAR gamma) is downregulated. This profile has been observed in several diseases 
[6] such as cancers [7, 8], type 2 diabetes [9], and certain neurodegenerative diseases (amyotrophic lateral sclerosis [10], Huntington's disease [11], multiple sclerosis [12, 13] and Friedreich's ataxia [14]). The opposite profile has been reported in arrhythmogenic right ventricular cardiomyopathy (ARVC) [15, 16], osteoporosis [17-19], and certain neurodegenerative diseases (Alzheimer's disease [20], Parkinson's disease [21], bipolar disorder [22, 23] and schizophrenia [24]). From a thermodynamic viewpoint and among numerous cellular processes involved in cancers, two major phenomena play a key role, i.e., aerobic glycolysis or the Warburg effect and disruption of circadian rhythms (CRs). The thermodynamic dysregulation induced by these two processes is consubstantial with metabolic abnormalities commonly found in cancers. PPAR dysfunction influences statistical mechanics by modifying thermodynamic force, thermodynamic flow, and rate of entropy production [5, 25]. We focus our review on the opposing interactions observed in cancers between the canonical WNT/beta-catenin pathway and PPAR gamma and their metabolic and energetic implications.

\section{Canonical WNT/beta-catenin pathway}

The canonical WNT/beta-catenin pathway plays an important role in metabolism, embryonic development, cell fate, and epithelial-mesenchymal transition (EMT) [26]. The canonical WNT activity is reflected by elevated levels of beta-catenin in the nucleus and/or cytoplasm, which can be detected by means of immunohistochemical staining, Western blotting and semiquantitative RT-PCR [27]. Its dysfunction is involved in numerous diseases, particularly in cancers [28-31]. The transcription factor beta-catenin/T-cell factor/lymphoid enhancer factor (TCF/LEF) represents the key effector of the canonical WNT pathway (Figs. 1, 2). The destruction complex consists of AXIN, tumor suppressor adenomatous polyposis coli (APC), and glycogen synthase kinase-3 (GSK-3beta). The destruction complex exerts a tight control on the beta-catenin signaling. In the absence of WNT ligands ("off state"), the destruction complex phosphorylates betacatenin which is then degraded in the proteasome. In the presence of WNT ligands ("on state"), the WNT receptor interacts with Frizzled (FZL) and LDL receptor-related protein 5/6 (LRP5/6). WNT receptor is associated with Dishevelled (DSH). This triggers the disruption of the destruction complex and prevents degradation of betacatenin in the proteasome. Beta-catenin then translocates to the nucleus and interacts with TCF/LEF. This leads to the stimulation of the beta-catenin target genes (pyruvate dehydrogenase kinase (PDK), monocarboxylate lactate transporter-1 (MTC-1), MYC, CYCLIN D1, cyclooxygenase-2 (COX-2), AXIN) [32-35] (Fig. 1).

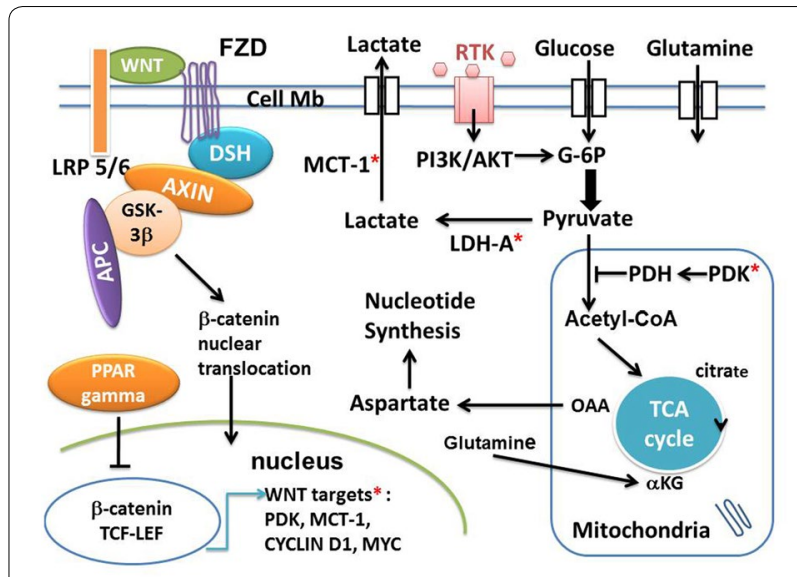

Fig. 1 Schema of interactions between the canonical WNT/ beta-catenin pathway and PPAR gamma under aerobic glycolysis conditions in cancer. In the absence of the WNT ligands ("off state"), cytosolic beta-catenin is phosphorylated by GSK-3 beta. APS and AXIN combine with GSK-3 beta and beta-catenin to enhance the destruction process in the proteasome. In the presence of the WNT ligands ("on state"), Wht binds both Frizzled and LRP5/6 receptors to initiate LRP phosphorylation and dishevelled-mediated Frizzled internalization. This leads to dissociation of the AXIN/APC/GSK-3 beta complex. Beta-catenin phosphorylation is inhibited which prevents its degradation in the proteasome. Thus, beta-catenin accumulates in the cytosol and then translocates to the nucleus to bind TCF-LEF COtranscription factors. This induces the WNT-response gene transcription (PDK, MCT-1, MYC, CYCLIN D1). Glucose itself activates the WNT pathway. PPAR gamma inhibits the beta-catenin/TCF-LEF-induced activation of WNT target genes. PDK inhibits the PDH complex in mitochondria. Thus pyruvate cannot be fully converted into acetylCOA and enter the TCA cycle. MYC activates LDH-A which converts cytosolic pyruvate into lactate. MCT-1 favors lactate extrusion out of the cytosol which favors angiogenesis. MYC increases glutamine entry in the cytosol and mitochondria. MYC-induced glutamine enhances aspartate and nucleotide synthesis. APC adenomatous polyposis coli, alpha-KG alpha ceto-glutarate, DSH Dishevelled, FZD Frizzled, GSK-3beta glycogen synthase kinase-3beta, LDH lactate dehydrogenase, LRP5/6 low-density lipoprotein receptor-related protein 5/6, MCT-1 monocarboxylate lactate transporter-1, OAA: oxalo-acetic acid, PPAR gamm peroxisome proliferator-activated receptor gamma, $P D H$ pyruvate dehydrogenase complex, PDK pyruvate dehydrogenase kinase, RTK receptor tyrosine kinase, TCF/LEF T-cell factor/lymphoid enhancer factor, TCA tricarboxylic acid, *WNT targets: PDK, MCT-1, MYC, CYCLIN D1

\section{PPAR gamma}

Peroxisome proliferator-activated receptor gamma is a ligand-activated transcriptional factor that belongs to the nuclear hormone receptor superfamily [36]. It heterodimerizes with the retinoid $\mathrm{X}$ receptor. PPAR gamma is expressed in numerous cell types, such as adipose tissues, muscles, brain, and immune cells. PPAR gamma activates the expression of many genes and regulates glucose homeostasis, insulin sensitivity, lipid metabolism, immune responses, cell fate and inflammation [3739]. PPAR gamma agonists thiazolidinediones (TZDs) 


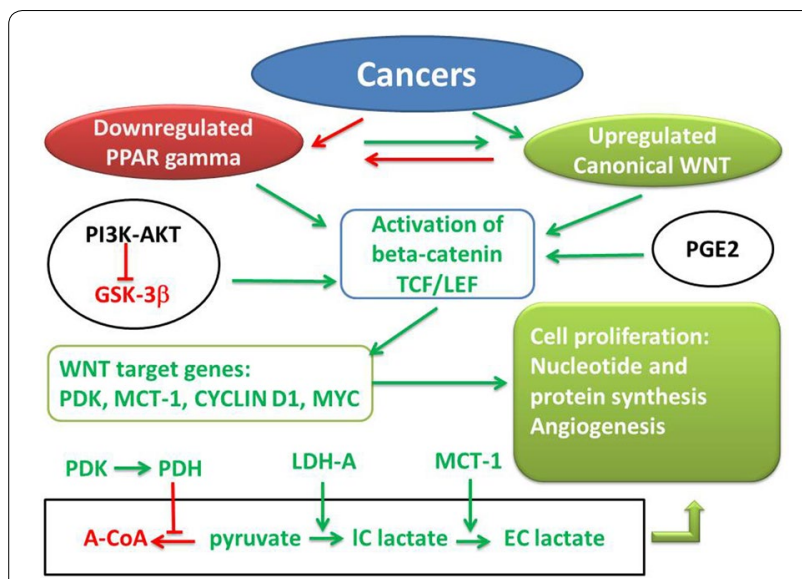

Fig. 2 Synthetic diagram of opposing effects of PPAR gamma and canonical WNT/beta-catenin signaling in cancer. Green arrow activation; red arrow inhibition; A-COA acetyl-COA, GSK-3beta glycogen synthase kinase-3beta, IC lactate intracellular lactate, EC lactate extracellular lactate, GSK-3beta glycogen synthase kinase-3beta, LDH-A lactico-dehydrogenase-A, MCT-1 monocarboxylate lactate transporter-1, PI3 K-AKT phosphatidylinositol 3-kinase-protein kinase $B, P D H$ pyruvate dehydrogenase, $P D K$ pyruvate dehydrogenase kinase, TCF/LEFT-cell factor/lymphoid enhancer factor, PPAR gamma peroxisome proliferator-activated receptor gamma

improve insulin sensitivity in peripheral tissues [40] and ameliorate glucose tolerance and insulin sensitivity in type 2 diabetic patients [41]. TZDs act on the promoters of glucose transporter (GLUT-2) and glucokinase (GK) in pancreatic beta-cells and liver. Abnormalities of PPAR gamma are observed in several pathological states such as cancers, diabetes, obesity, and atherosclerosis. Some TZDs have been used for treating type 2 diabetes. PPAR gamma also plays an important role in regulating cardiovascular rhythms by controlling circadian variations of blood pressure and heart rate through BMAL1 [42, 43]. However, numerous side effects induced by TZD have been reported [44].

\section{Opposing effects of the canonical WNT/beta-catenin pathway and PPAR gamma}

The link between the WNT/beta-catenin pathway and PPAR gamma involves the TCF/LEF beta-catenin-binding domain and a catenin binding domain within PPAR gamma. In numerous mammalian cells, PPAR gamma and WNT/beta-catenin signaling behave in an opposite manner [45-50]. In some diseases, although the WNT/ beta-catenin pathway is downregulated, PPAR gamma appears to be upregulated and vice versa (see: "Introduction") [6]. In several cellular systems, beta-catenin is inhibited by PPAR gamma agonists [45, 47, 48, 51]. It has also been observed that inhibition of the WNT/betacatenin pathway induces activation of PPAR gamma [15].
Aerobic glycolysis in cancer cells: role of the canonical WNT signaling

The role of the WNT/beta-catenin signaling in cancer development, especially in colorectal cancer, is now better understood $[52,53]$. Upregulation of the WNT/betacatenin pathway via TCF/LEF leads to cell proliferation, EMT, migration and angiogenesis [54-56]. In cancer cells, overactivation of the WNT/beta-catenin pathway induces aerobic glycolysis. This allows glucose utilization for cell proliferation [35]. Thus in a large part, glucose supply is fermented in lactate regardless of oxygen availability. This phenomenon is referred to as aerobic glycolysis or the Warburg effect [57].

In cancer, the behavior of two key enzymes involved in glucose metabolism is modified leading to the Warburg effect. Activation of PDK-1 is required for the Warburg aerobic glycolysis. Upregulation of WNT/beta-catenin signaling activates both PDK-1 and MCT-1 [35, 58]. PDK-1, a major regulator of glucose metabolism, phosphorylates the pyruvate dehydrogenase complex (PDH) which is inhibited and largely prevents the conversion of pyruvate into acetyl-CoA in mitochondria [59]. In colon cancer, PDK- 1 is upregulated $[35,60]$, so that the conversion of pyruvate into acetyl-CoA in mitochondria is diminished with a consequent reduction of acetylCoA entering the tricarboxylic acid (TCA) cycle. This induces aerobic glycolysis in spite of the availability of oxygen. PDK-1 has also been observed to be upregulated in several other cancers $[61,62]$. Cytosolic pyruvate is converted into lactate through activation of lactic dehydrogenase-A (LDH-A). Upregulation of both LDH-A and $\mathrm{MCT}-1$ results in pyruvate being diverted towards the formation of lactate and the secretion of the latter outside of the cell, which favors angiogenesis [63] and ultimately leads to anabolic production of biomass i.e., nucleotide synthesis $[64,65]$. The Warburg effect partly shunts the TCA cycle leading to aerobic glycolysis which is less efficient in terms of ATP production. The most cost effective way producing ATP is via glucose oxidation $\left(\mathrm{ATP} / \mathrm{O}_{2}=6.4\right)$, since the pathway via free fatty acid beta-oxidation is less efficient $\left(\mathrm{ATP} / \mathrm{O}_{2}=5.6\right)$. This takes about $11 \%$ more $\mathrm{O}_{2}$ to produce the same amount of ATP from fatty acids as it does from glucose. Moreover, PDK-1 and 2 enhance angiogenesis $[66,67]$. Blocking WNT reduces the PDK-1 level via the transcription regulation and reduces in vivo tumor growth [35]. Conversely, PPAR gamma activation selectively decreases PDK mRNA [68]. PDKs allow metabolic flexibility [69] and are transcriptionally regulated by insulin, glucocorticoids, thyroid hormone and fatty acids [70]. Several diseases presenting PDK abnormalities are often associated with type 2 diabetes, obesity, metabolic disorders, cardiomyopathies, neuropathies and cancers. 
In colon cancer, activation of WNT/beta-catenin signaling decreases the oxidative metabolism in the TCA cycle and promotes cell proliferation [35]. In addition, the $\mathrm{WNT} /$ beta-catenin pathway induces the transcription of genes involved in cell proliferation, particularly CYCLIN D1 and MYC operating through the G1 phase [71-74]. MYC activates aerobic glycolysis and glutaminolysis and favors nucleotide synthesis [75, 76]. MYC also activates LDH-A, induces glutamine uptake into the cell and mitochondria, and stimulates aspartate synthesis which favors nucleotide synthesis [75] (Fig. 1). Moreover, MYC increases the hypoxia-inducible factor -1alpha (HIF1A) which controls PDK-1 [77]. Part of the pyruvate is converted into acetyl-CoA which in turn enters the TCA cycle and is converted into citrate. This promotes protein and lipid synthesis. Cellular accumulation of metabolic intermediates (aspartate, serine, glycine, and ribose) allows de novo nucleotide synthesis, which contributes to growth and proliferation.

Phosphofructokinase (PFK), an allosteric enzyme, is responsible for glycolytic oscillations. PFK can lead to instabilities beyond which a new state can be organized in time and in space [78]. A positive feedback is responsible for periodic behavior. These far-from-equilibrium oscillatory mechanisms come within the field of dissipative structures initially described by Illia Prigogine [79]. Elevated PFK-1 activity is characteristic of cancer cells and is induced in response to oncogenes [80].

Cancer cells are characterized by increased glucose consumption. High serum glucose levels may modulate cancer-related processes. Glucose itself can directly impact the canonical WNT pathway [81]. High glucose level enhances the nuclear translocation of beta-catenin in response to WNT activation. In cancer cells, glucose-induced beta-catenin acetylation favors the WNT pathway.

\section{Aerobic glycolysis and vitamin C}

It has been recently described a novel antitumoral mechanism of vitamin C [82]. Mutation of the proto-oncogene KRAS is often present in colon and pancreatic cancer. In KRAS mutant colorectal cancer, this mechanism involves the Warburg metabolic disruption. In the absence of vitamin C, pyruvate kinase PKM2 is phosphorylated, then translocates to the nucleus and binds the beta-catenin/ TCF/LEF transcriptional factor. This promotes the MYC transcription which in turn enhances GLUT-1 and Polypyrimidine Tract Binding Protein (PTB) expression. In the presence of vitamin $C$ which enters into the cell via GLUT-1, RAS is detached from the cell membrane which blocks the PKM2 phosphorylation. This induces downregulation of GLUT-1 and PKM2 expression via disruption of the beta-catenin/TEF/LEF transcriptional complex. This leads to downregulation of MYC and inhibition of the Warburg pathway. Thus, vitamin $\mathrm{C}$ uncouples the Warburg metabolic switch in KRAS mutant colon cancer.

\section{Thermodynamics and lawless-disorderly cancer growth}

From a thermodynamic viewpoint, the lawless-disorderly cancer growth and the orderly fetal growth share some similar features [83]. Hypoxic conditions reported in cancer cells for their growth requirements resemble to those observed during normal fetal growth, which requires a relatively low oxygen tension. For both cancerous and fetal growth, low energy requirements are linked to the tumorigenic arm of acute inflammation [83], as in wound healing. Moreover, the production of lactate under aerobic glycolysis conditions is characteristic of the human placenta [84], a tissue in which the population of contractile myofibroblasts is important [85]. In cancer (mammary carcinoma, epithelial cells in cancerous mammary glands), fibrotic lesions (Dupuytrens nodules, hypertrophic scars) [86], and normal placental stem villi [87], the main myosin molecular motor in myofibroblasts is the non muscle myosin (NMM). Kinetics of contractile NMM crossbridges are dramatically slow [88] and their entropy production rate is extremely low [89]. The presence of numerous myofibroblasts is associated with the aerobic glycolysis metabolism. In epithelial cancers, myofibroblasts represent a significant part of the stroma reaction. Myofibroblasts, epithelial cells, and connective tissue cells participate to cancer invasion, with loss of epithelial characteristics and acquisition of mesenchymal properties. This refers to as EMT [26] which greatly influences the invasive carcinoma progression and in which the canonical WNT pathway plays a key role. WNT3a favors myofibroblast differentiation by upregulating the transforming growth factor (TGF-beta1). This occurs through SMAD2 in a beta-catenin-dependent manner [90]. Importantly, it has been recently demonstrated that aerobic glycolysis is induced in response to TGF-beta1 [91].

\section{Activation of WNT/beta-catenin pathway and inactivation of PPAR gamma in cancers}

WNT/beta-catenin signaling has been found to be activated in cancers $[92,93]$. WNT1 was first discovered as a proto-oncogene in a breast cancer mouse model. Increased expression of beta-catenin may be due to factors such as mutations in beta-catenin, abnormalities in the beta-catenin destruction complex, mutations in APC, overexpression of WNT ligands, and loss of inhibition or decreased activity of regulatory pathways. Alterations in gene expression of CTNNB1 which encodes beta-catenin, have been reported in numerous cancers such as breast 
colorectal, melanoma, prostate and lung tumors. WNT 1, WNT2 and WNT7A ligand-proteins are overexpressed in glioblastoma, esophageal cancer and ovarian cancer respectively. Proteins of the TCF/LEF family and WNT5A may also induce cancer. Repression of WNT/ beta-catenin signaling can prevent EMT and inhibit metastasis. Mutations of the WNT pathway components are associated with many cancers, particularly with colorectal cancer. APC deficiency and beta-catenin mutations upregulate the WNT/beta-catenin pathway and prevent beta-catenin degradation. This leads to excessive stem cell renewal and cell proliferation that predisposes to tumor genesis particularly for colorectal cancer [94]. Nuclear accumulation of beta-catenin drives cancer cell proliferation. In colon cancer, beta-catenin-TCF/LEF signaling is activated [95], and activation of the WNT pathway via $A P C$ gene mutations favors cell proliferation [96]. Mutations in PPAR gamma are linked with human colon cancer [97].

Several studies have presented evidence for a protective role of PPAR gamma against cancer. In colon cancer, PPAR gamma downregulates the oncogene beta-catenin and suppresses cell proliferation [98]. In contrast, other studies have implicated PPAR gamma in the promotion and development of cancer [8]. Thus, PPAR gamma activation by specific agonists can induce growth inhibition, apoptosis and differentiation of numerous tumor cells. On the contrary, overexpression of PPAR gamma has been reported in tumors of colon, breast, prostate, stomach, salivary gland, cervix, ovary, bladder, lung, testes and the neural crest element of sympathetic nervous system [7]. The biological significance of PPAR gamma in cancer remains controversial. Activation of PPAR gamma can induce either tumor suppressive or promoting responses. On the one hand, PPAR gamma can act as a tumor inhibitor in colon cancer [99-105], in breast cancer [106-110], in urological cancer [110-115], in lung cancer [116-118], and in gastric cancer [119-122]. On the other hand, PPAR gamma can act as a tumor promotor in colon cancer [123-126], in breast cancer [127-132], and in urological cancer [133-135]. There is no clear unifying accepted mechanism explaining these contradictory evidences concerning either the protective role of PPAR gamma or their role on promotion/development of cancer. This might be partly explained by cell type-specific effects, organ-specific effects, receptor-independent effects according to the PPAR gamma agonist used. This might also be due to specific pharmacokinetic properties of PPAR gamma ligands or the stage of cancer development at which the PPAR gamma ligand is administered [8]. These arguments are hypotheses, and for the time being, no universal mechanism is able to explain the contradictory effects of PPAR gamma ligands on cancers.
Role of PI3K-AKT pathway in aerobic glycolysis and cancers Hyperactivation of phosphatidylinositol 3-kinase (PI3K)protein kinase $\mathrm{B}(\mathrm{AKT})$ pathway is associated with an increased rate of glucose metabolism in tumor cells [136]. AKT signaling directly acts on aerobic glycolysis in cancer cells. AKT regulates the localization of GLUT1 in the plasma membrane and hexokinase expression. It also activates phosphofructokinase-1 (PFK-1) which directly phosphorylates PFK-2. This leads to produce fructose2.6-bisphosphate, an activator of PFK-1. AKT activation causes an increase in aerobic glycolysis or Warburg effect in cancer. PI3K-AKT pathway promotes cell survival, cell growth, cell proliferation, cell migration and angiogenesis in response to extracellular signals including hormones and growth factors. This pathway is stimulated by the binding of extracellular ligands to a receptor tyrosine kinase (RTK) located in the plasma membrane (Fig. 1). This signaling is upregulated in certain cancers. Through phosphorylation of GSK-3beta, PI3 K-AKT favors the G1 phase of the cell cycle. GSK-3beta phosphorylation decreases the degradation of beta-catenin in the proteasome. Thus, TCF/LEF transcription factor is activated which in turn favors transcription of the target gene CYCLIN D1 [137]. Consequently, by decreasing the GSK-3beta activity, AKT pathway behaves similarly to the WNT pathway. Aberrant activation of PI3K-AKT is often associated with cancers, including glioblastomas, ovarian, pancreatic and breast cancers [138]. AKT mRNA is increased in breast and prostate cancer. PI3KAKT contributes to angiogenesis by acting on the vascular endothelial growth factor in endothelial cells and on the endothelial nitric oxide synthase. This activates vasodilation and vascular remodeling [139]. Moreover, the PI3K-AKT pathway increases the hypoxia-inducible transcription factor [140].

The phosphatase and tensin homologue (PTEN) represents the main brake of the PI $3^{\prime}-\mathrm{OH}$ kinase (PIK3)-AKT pathway [141]. PI3K generate phosphatidylinositol-3,4,5triphosphate (PIP3) from PIP2. AKT is activated by PIP3. PTEN is a PIP3-phosphatase and its activity is opposed to that of PI3K. PI3K-AKT signaling is a major pathway which is activated in cancer. PTEN appears to be relevant against cancer progression and represents a target for somatic cancer inactivation. In some cancers (endometrial, breast, and colorectal cancers), PI3K and PTEN mutations coexist. PTEM also induces a decrease in cancer cell proliferation due to cell cycle arrest in the G1 phase.

\section{Prostaglandins, WNT and PPAR gamma}

Several studies have established the role of prostaglandin E2 (PGE2) by activating the WNT/beta-catenin pathway. The link between PGE2 and the canonical WNT 
pathway suggests that chronic inflammation induced by a prolonged increase of PGE2 could lead to activation of WNT signaling resulting in cell proliferation and cancer. PGE2 enhances the beta-catenin-dependent transcription [142, 143]. PGE2 promotes colon cancer cell growth through the beta-catenin pathway. Thus, blockage of WNT/beta-catenin signaling can be of interest for cancer treatment. In treatment of colorectal cancer, nonsteroidal anti-inflammatory drugs (NSAIDs) induce beneficial effects [144], partly due to their interaction with the beta-catenin pathway and their inhibition of the PGE2 synthesis. PGE2 modulates the WNT activity in hematopoietic stem cell (HSC) in zebrafish. Inhibition of PGE2 synthesis blocks alterations in HSC induced by WNT. PGE2 modifies the WNT signaling cascade at the level of beta-catenin degradation through the cAMP/PKA pathway. WNT activation in stem cells requires PGE2 [145]. Dimethyl-prostaglandin E2 increases HSC in vivo. In addition, dimethyl-prostaglandin E2 leads to the formation of components of the WNT pathway [146]. WNT signaling upregulates interleukin (IL)-7R and IL-2Rbeta. In neuroectodermal (NE-4C) stem cells, PGE2 interacts with the canonical WNT signaling through PKA and PI3K [147]. In WNT-induced cells, beta-catenin is increased and the WNT-target genes (Ctnnb1, Ptgs2, Ccnd1, Mmp9) are significantly upregulated after PGE2 use. PPAR gamma and proinflammatory enzyme pathways are interrelated. Decreased expression of PPAR gamma and high levels of COX-2 have been reported in many cancers [148]. TZDs decrease COX-2, inhibit growth of non-small-cell lung cancer cells in vitro, and block tumor development. TZDs diminish COX-2 and PGE2 through PPAR gamma. The PPAR gamma activator $15 \mathrm{dPG} 2$ plays an anti-inflammatory role in a PPAR gamma-dependent manner, decreasing COX-2, PGE2 and iNos expression [149].

\section{Circadian rhythms (CRs), cancers, metabolism and thermodynamics}

CRs can be defined as endogenous, entrainable free-running periods that last approximately $24 \mathrm{~h}$. CRs are farfrom-equilibrium dissipative structures and are due to a negative feedback produced by a protein on the expression of its own gene [150-152]. They operate in farfrom-equilibrium manner if affinity of the studied system is $\gg \mathrm{RT}$ ( $\mathrm{R}$ is the universal gas constant and $\mathrm{T}$ is the absolute temperature), and generate order spontaneously by exchanging energy with their external environment [2, 153]. In mammals, CRs involve several major critical transcription factors such as circadian locomotor output cycles kaput (CLOCK), brain and muscle aryl-hydrocarbon receptor nuclear translocator-like1 (BMAL1), period 1 (PER1), period 2 (PER2), and period 3 (PER3) [154,
155]. Transcription/translation autoregulatory feedback loops with both activating and inhibiting pathways are involved in CRs [156, 157].

Circadian rhythms govern numerous physiological and metabolic functions [158]. Thus, CRs are observed in sleep-awake and feeding patterns, energy metabolism, body temperature, hormone secretion, heart rate and blood pressure. Following epidemioloigical and genetic probes, it has been suggested that disruption of CRs may be directly linked to cancer, leading to aberrant cellular proliferation [159]. Since numerous connections between the circadian clock and cellular metabolism have been reported, it is thougth that the abnormal metabolism observed in cancer may be a consequence of disrupted CRs. CRs within the cell regulate the timing of many important life cycles [160]. The phase diffusion constant depends on the free-energy dissipation per period. Oscillations are driven by multiple irreversible cycles that hydrolyze fuel molecules such as ATP. The free energy consumed per period is proportional to the number of phase coherent periods. A decreased BMAL1 function modifies the behavior of genes involved in the canonical WNT pathway [161]. Beta-catenin induces PER2 degradation altering circadian clock gene in intestinal mucosa of ApcMin/+ mice [162]. A deceased expression level of PER1 and/or PER2 has been reported in numerous cancers: breast cancer [163], prostate cancer [164], pancreatic cancer [165], colorectal cancer [166], chronic myeloid leukemia [167], and glioma [168, 169].

Peroxisome proliferator-activated receptors interferes with the mammalian clock and energy metabolism [170]. PPARs are rhythmically expressed in mammalian tissues [171] and directly interact with the core clock genes. PPAR gamma exhibits variations in diurnal expression in mouse fat, liver and blood vessels [42]. Deletion of PPAR gamma in mouse impairs diurnal rhythms [172]. PPAR gamma plays an important role in the coordinated control of circadian clocks, metabolism and cardiac performance. PGC-1 alpha, a transcriptional co-activator that regulates energy metabolism, is rhythmically expressed in the liver and skeletal muscle of mice. PGC-1 alpha upregulates the expression of the clock genes BMAL1 and Rev-erb alpha. Mice lacking PGC-1 alpha show changes in CRs and metabolism [173]. PGC-1 alpha acts as a stress sensor in cancer cells. In maintaining metabolic homeostasis, PGC-1 alpha favors cancer cell survival [174]. PGC-1 alpha interfers in a very complex manner with nuclear receptors such as Rev-erb, ROR, PPARs [175]. PPAR alpha and gamma up-regulate the expression of Rev-erb alpha and BMAL1 by binding to their promotors. PGC-1 potentiates ROR alpha transcriptional activity and enhances both Rev-erb alpha and BMAL1 transcription. Moreover after serum shock, 
GSK-3beta-mediated stabilization of Rev-erb alpha plays a key role to initiate, maintain and synchronize CRs.

\section{Conclusions}

Cancers exhibit thermodynamic and metabolic alterations and abnormal CRs. In many cancers but not all, the canonical WNT/beta-catenin pathway is upregulated, while PPAR gamma is downregulated, the two systems behaving in an opposite manner. Overactivation of the WNT pathway results in cell proliferation due to the activation of certain target genes of beta-catenin, such as MYC and CYCLIN D1. This promotes protein synthesis and angiogenesis. $P D K$ and $M C T-1$ are also target genes of beta-catenin, explaining the significant decrease in the transformation of pyruvate into acetyl-CoA in mitochondria and the formation of intracellular lactate, which will be extruded out of the cell. This is referred to as aerobic glycolysis or the Warburg phenomenon. The expression of PPAR gamma is decreased due to the overactivation of WNT/beta-catenin signaling. Circadian rhythms, dissipative structures which are governed by the laws of far-from-equilibrium thermodynanics are disrupted in cancers. They are influenced by both the WNT/betacatenin pathway and PPAR gamma. Changes in thermodynamics, metabolism and circadian rhythms are tightly linked in cancers.

\begin{abstract}
Abbreviations
acetyl-CoA: acetyl-coenzyme A; APC: adenomatous polyposis coli; ARVC: arrhythmogenic right ventricular dysplasia/cardiomyopathy; BMAL1: brain and muscle aryl-hydrocarbon receptor nuclear translocator-like1; CLOCK: circadian locomotor output cycles kaput; COX-2: cyclooxygenase-2; DSH: dishevelled; EMT: epithelial-mesenchymal transition; FZD: frizzled; GK: glucokinase; GLUT: glucose transporter; GSK-3beta: glycogen synthase kinase-3beta; HSC: hematopoietic stem cell; LDH: lactate dehydrogenase; LRP5/6: low-density lipoprotein receptor-related protein 5/6; MCT-1: monocarboxylate lactate transporter-1; NSAID: nonsteroidal anti-inflammatory drug; PER: period; PPAR: peroxisome proliferator-activated receptor; PGC-1 alpha: peroxisome proliferator-activated receptor-gamma coactivator-1 alpha; PI3K-AKT: phosphatidylinositol 3-kinase-protein kinase B; PFK-1: phosphofructokinase-1; PGE2: prostaglandin E2; PDH: pyruvate dehydrogenase complex; PDK: pyruvate dehydrogenase kinase; RTK: receptor tyrosine kinase; TCF/LEF: T cell factor factor/lymphoid enhancer factor; TZD: thiazolidinedione; TGF-beta1: transforming growth factor; TCA: tricarboxylic acid.
\end{abstract}

\section{Authors' contributions}

YL, VC, AV and J-LH have contributed equally to this review. All authors read and approved the final manuscript.

\section{Author details \\ ${ }^{1}$ Centre de Recherche Clinique, Hôpital de Meaux, 6-8 rue Saint Fiacre, 77100 Meaux, France. ${ }^{2}$ Department of Pharmaceutical Sciences, University of Antwerp, Wilrijk, Belgium. ${ }^{3}$ Experimental and Clinical Neurosciences Laboratory, INSERM U1084, University of Poitiers, Poitiers, France. ${ }^{4}$ Institut de Cardiologie, Hôpital de la Pitié-Salpêtrière, Assistance Publique-Hôpitaux de Paris, Paris, France.}

\section{Acknowledgements}

We would like to thank Dr. Christophe Locher, President of the "Fédération de la Recherche Clinique du Grand Hôpital de I'Est Francilien", and Mr. Vincent Gobert, Administrative Manager of the Clinical Research Center, Meaux
Hospital, Meaux, France, for their valuable support in making the necessary research facilities available for this study. The manuscript has been revised by Brian Keogh, Ph.D.

\section{Competing interests}

The authors declare that they have no competing interests.

\section{Publisher's Note}

Springer Nature remains neutral with regard to jurisdictional claims in published maps and institutional affiliations.

Received: 28 November 2016 Accepted: 20 March 2017

Published online: 12 April 2017

References

1. Schrödinger E (1944) What is life?: Cambridge University Press, Cambridge

2. Prigogine I, Nicolis G, Babloyantz A (1974) Nonequilibrium problems in biological phenomena. Ann NY Acad Sci 231:99-105

3. Prigogine I (1986) Life and physics. New perspectives. Cell Biophys 9:217-224

4. Atkins PW (1990) Physical chemistry. Oxford University Press, Oxford, pp $1-1031$

5. Kondepudi D, Prigogine I (1999) Modern thermodynamics from heat engines to dissipative structures. Wiley, New York, pp 1-486

6. Lecarpentier Y, Claes V, Duthoit G, Hebert JL (2014) Circadian rhythms, Wnt/beta-catenin pathway and PPAR alpha/gamma profiles in diseases with primary or secondary cardiac dysfunction. Front Physiol 5:429

7. Krishnan A, Nair SA, Pillai MR (2007) Biology of PPAR gamma in cancer: a critical review on existing lacunae. Curr Mol Med 7:532-540

8. Youssef J, Badr M (2011) Peroxisome proliferator-activated receptors and cancer: challenges and opportunities. Br J Pharmacol 164:68-82

9. Lecarpentier Y, Claes V, Vallee A, Hébert JL (2017) Interactions between PPAR gamma and the canonical Wnt/beta-catenin pathway in type 2 diabetes and colon cancer. PPAR Res 5:1-9

10. Lecarpentier $Y$, Vallee A (2016) Opposite interplay between PPAR gamma and canonical Wnt/Beta-catenin pathway in amyotrophic lateral sclerosis. Front Neurol 7:100

11. Godin JD, Poizat G, Hickey MA, Maschat F, Humbert S (2010) Mutant huntingtin-impaired degradation of beta-catenin causes neurotoxicity in Huntington's disease. EMBO J 29:2433-2445

12. Drew PD, Xu J, Racke MK (2008) PPAR-gamma: therapeutic potential for multiple sclerosis. PPAR Res 2008:627463

13. Yuan S, Shi Y, Tang SJ (2012) Wnt signaling in the pathogenesis of multiple sclerosis-associated chronic pain. J Neuroimmune Pharmacol 7:904-913

14. Coppola G, Marmolino D, Lu D, Wang Q, Cnop M et al (2009) Functional genomic analysis of frataxin deficiency reveals tissue-specific alterations and identifies the PPARgamma pathway as a therapeutic target in Friedreich's ataxia. Hum Mol Genet 18:2452-2461

15. Garcia-Gras E, Lombardi R, Giocondo MJ, Willerson JT, Schneider MD et al (2006) Suppression of canonical Wnt/beta-catenin signaling by nuclear plakoglobin recapitulates phenotype of arrhythmogenic right ventricular cardiomyopathy. J Clin Invest 116:2012-2021

16. Djouadi F, Lecarpentier Y, Hebert JL, Charron P, Bastin J et al (2009) A potential link between peroxisome proliferator-activated receptor signalling and the pathogenesis of arrhythmogenic right ventricular cardiomyopathy. Cardiovasc Res 84:83-90

17. Canalis E (2013) Wnt signalling in osteoporosis: mechanisms and novel therapeutic approaches. Nat Rev Endocrinol 9:575-583

18. Rawadi G, Roman-Roman S (2005) Wnt signalling pathway: a new target for the treatment of osteoporosis. Expert Opin Ther Targets 9:1063-1077

19. Korvala J, Juppner H, Makitie O, Sochett E, Schnabel D et al (2012) Mutations in LRP5 cause primary osteoporosis without features of OI by reducing Wnt signaling activity. BMC Med Genet 13:26

20. Vallee A, Lecarpentier Y (2016) Alzheimer disease: crosstalk between the canonical Wnt/beta-catenin pathway and PPARs alpha and gamma. Front Neurosci 10:459 
21. Berwick DC, Harvey K (2012) The importance of Wnt signalling for neurodegeneration in Parkinson's disease. Biochem Soc Trans 40:1123-1128

22. Gould TD, Manji HK (2002) The Wnt signaling pathway in bipolar disorder. Neuroscientist 8:497-511

23. Valvezan AJ, Klein PS (2012) GSK-3 and Wnt signaling in neurogenesis and bipolar disorder. Front Mol Neurosci 5:1

24. Panaccione I, Napoletano F, Forte AM, Kotzalidis GD, Del Casale A et al (2013) Neurodevelopment in schizophrenia: the role of the wnt pathways. Curr Neuropharmacol 11:535-558

25. Lecarpentier Y, Krokidis X, Martin P, Pineau T, Hebert JL et al (2008) Increased entropy production in diaphragm muscle of PPAR alpha knockout mice. J Theor Biol 250:92-102

26. Heuberger J, Birchmeier W (2010) Interplay of cadherin-mediated cell adhesion and canonical wnt signaling. Cold Spring Harb Perspect Biol 2:a002915

27. Igota S, Tosa M, Murakami M, Egawa S, Shimizu H et al (2013) Identification and characterization of Wnt signaling pathway in keloid pathogenesis. Int J Med Sci 10:344-354

28. Moon RT, Bowerman B, Boutros M, Perrimon N (2002) The promise and perils of Wnt signaling through beta-catenin. Science 296:1644-1646

29. Moon RT, Kohn AD, De Ferrari GV, Kaykas A (2004) WNT and betacatenin signalling: diseases and therapies. Nat Rev Genet 5:691-701

30. Nusse R (2005) Wnt signaling in disease and in development. Cell Res $15: 28-32$

31. Clevers $\mathrm{H}$ (2006) Wnt/beta-catenin signaling in development and disease. Cell 127:469-480

32. He TC, Sparks AB, Rago C, Hermeking H, Zawel L et al (1998) Identification of c-MYC as a target of the APC pathway. Science 281:1509-1512

33. Shtutman M, Zhurinsky J, Simcha I, Albanese C, D'Amico M et al (1999) The cyclin D1 gene is a target of the beta-catenin/LEF-1 pathway. Proc Natl Acad Sci USA 96:5522-5527

34. Angers S, Moon RT (2009) Proximal events in Wnt signal transduction. Nat Rev Mol Cell Biol 10:468-477

35. Pate KT, Stringari C, Sprowl-Tanio S, Wang K, TeSlaa T et al (2014) Wnt signaling directs a metabolic program of glycolysis and angiogenesis in colon cancer. EMBO J 33:1454-1473

36. Tyagi S, Gupta P, Saini AS, Kaushal C, Sharma S (2011) The peroxisome proliferator-activated receptor: a family of nuclear receptors role in various diseases. J Adv Pharm Technol Res 2:236-240

37. Elbrecht A, Chen Y, Cullinan CA, Hayes N, Leibowitz M et al (1996) Molecular cloning, expression and characterization of human peroxisome proliferator activated receptors gamma 1 and gamma 2. Biochem Biophys Res Commun 224:431-437

38. Fajas L, Auboeuf D, Raspe E, Schoonjans K, Lefebvre AM et al (1997) The organization, promoter analysis, and expression of the human PPAR gamma gene. J Biol Chem 272:18779-18789

39. Desvergne B, Wahli W (1999) Peroxisome proliferator-activated receptors: nuclear control of metabolism. Endocr Rev 20:649-688

40. Rangwala SM, Lazar MA (2004) Peroxisome proliferator-activated receptor gamma in diabetes and metabolism. Trends Pharmacol Sci 25:331-336

41. Picard F, Auwerx J (2002) PPAR(gamma) and glucose homeostasis. Annu Rev Nutr 22:167-197

42. Wang N, Yang G, Jia Z, Zhang H, Aoyagi T et al (2008) Vascular PPARgamma controls circadian variation in blood pressure and heart rate through Bmal1. Cell Metab 8:482-491

43. Lecarpentier Y, Claes V, Hebert JL (2010) PPARs, cardiovascular metabolism, and function: near- or far-from-equilibrium pathways. PPAR Res. doi:10.1155/2010/783273

44. Ahmadian M, Suh JM, Hah N, Liddle C, Atkins AR et al (2013) PPARgamma signaling and metabolism: the good, the bad and the future. Nat Med 19:557-566

45. Gerhold DL, Liu F, Jiang G, Li Z, Xu J et al (2002) Gene expression profile of adipocyte differentiation and its regulation by peroxisome proliferator-activated receptor-gamma agonists. Endocrinology 143:2106-2118

46. Girnun GD, Domann FE, Moore SA, Robbins ME (2002) Identification of a functional peroxisome proliferator-activated receptor response element in the rat catalase promoter. Mol Endocrinol 16:2793-2801

47. Sharma C, Pradeep A, Wong L, Rana A, Rana B (2004) Peroxisome proliferator-activated receptor gamma activation can regulate betacatenin levels via a proteasome-mediated and adenomatous polyposis coli-independent pathway. J Biol Chem 279:35583-35594
48. Takada I, Kouzmenko AP, Kato S (2009) Wnt and PPARgamma signaling in osteoblastogenesis and adipogenesis. Nat Rev Rheumatol 5:442-447

49. Lu D, Carson DA (2010) Repression of beta-catenin signaling by PPAR gamma ligands. Eur J Pharmacol 636:198-202

50. Liu J, Wang H, Zuo Y, Farmer SR (2006) Functional interaction between peroxisome proliferator-activated receptor gamma and beta-catenin. Mol Cell Biol 26:5827-5837

51. Moldes M, Zuo Y, Morrison RF, Silva D, Park BH et al (2003) Peroxisomeproliferator-activated receptor gamma suppresses Wnt/beta-catenin signalling during adipogenesis. Biochem J 376:607-613

52. Thompson CB (2014) Wnt meets Warburg: another piece in the puzzle? EMBO J 33:1420-1422

53. Bienz M, Clevers H (2000) Linking colorectal cancer to Wnt signaling. Cell 103:311-320

54. Brabletz T, Hlubek F, Spaderna S, Schmalhofer O, Hiendlmeyer E et al (2005) Invasion and metastasis in colorectal cancer: epithelial-mesenchymal transition, mesenchymal-epithelial transition, stem cells and beta-catenin. Cells Tissues Organs 179:56-65

55. Klaus A, Birchmeier W (2008) Wnt signalling and its impact on development and cancer. Nat Rev Cancer 8:387-398

56. Clevers H, Nusse R (2012) Wnt/beta-catenin signaling and disease. Cell 149:1192-1205

57. Warburg O (1956) On the origin of cancer cells. Science 123:309-314

58. Pinheiro C, Longatto-Filho A, Scapulatempo C, Ferreira L, Martins S et al (2008) Increased expression of monocarboxylate transporters 1, 2, and 4 in colorectal carcinomas. Virchows Arch 452:139-146

59. Roche TE, Baker JC, Yan X, Hiromasa Y, Gong X et al (2001) Distinct regulatory properties of pyruvate dehydrogenase kinase and phosphatase isoforms. Prog Nucleic Acid Res Mol Biol 70:33-75

60. Koukourakis Ml, Giatromanolaki A, Harris AL, Sivridis E (2006) Comparison of metabolic pathways between cancer cells and stromal cells in colorectal carcinomas: a metabolic survival role for tumor-associated stroma. Cancer Res 66:632-637

61. Wigfield SM, Winter SC, Giatromanolaki A, Taylor J, Koukourakis ML et al (2008) PDK-1 regulates lactate production in hypoxia and is associated with poor prognosis in head and neck squamous cancer. Br J Cancer 98:1975-1984

62. Baumunk D, Reichelt U, Hildebrandt J, Krause H, Ebbing J et al (2013) Expression parameters of the metabolic pathway genes pyruvate dehydrogenase kinase-1 (PDK-1) and DJ-1/PARK7 in renal cell carcinoma (RCC). World J Urol 31:1191-1196

63. Hunt TK, Aslam RS, Beckert S, Wagner S, Ghani QP et al (2007) Aerobically derived lactate stimulates revascularization and tissue repair via redox mechanisms. Antioxid Redox Signal 9:1115-1124

64. DeBerardinis RJ, Lum JJ, Hatzivassiliou G, Thompson CB (2008) The biology of cancer: metabolic reprogramming fuels cell growth and proliferation. Cell Metab 7:11-20

65. Vander Heiden MG, Cantley LC, Thompson CB (2009) Understanding the Warburg effect: the metabolic requirements of cell proliferation. Science 324:1029-1033

66. McFate T, Mohyeldin A, Lu H, Thakar J, Henriques J et al (2008) Pyruvate dehydrogenase complex activity controls metabolic and malignant phenotype in cancer cells. J Biol Chem 283:22700-22708

67. Sutendra G, Dromparis P, Kinnaird A, Stenson TH, Haromy A et al (2013) Mitochondrial activation by inhibition of PDKIl suppresses HIF1a signaling and angiogenesis in cancer. Oncogene 32:1638-1650

68. Abbot EL, McCormack JG, Reynet C, Hassall DG, Buchan KW et al (2005) Diverging regulation of pyruvate dehydrogenase kinase isoform gene expression in cultured human muscle cells. FEBS J 272:3004-3014

69. Zhang S, Hulver MW, McMillan RP, Cline MA, Gilbert ER (2014) The pivotal role of pyruvate dehydrogenase kinases in metabolic flexibility. Nutr Metab (Lond) 11:10

70. Lee IK (2014) The role of pyruvate dehydrogenase kinase in diabetes and obesity. Diabetes Metab J 38:181-186

71. Osthus RC, Shim H, Kim S, Li Q, Reddy R et al (2000) Deregulation of glucose transporter 1 and glycolytic gene expression by c-Myc. J Biol Chem 275:21797-21800

72. van de Wetering M, Sancho E, Verweij C, de Lau W, Oving I et al (2002) The beta-catenin/TCF-4 complex imposes a crypt progenitor phenotype on colorectal cancer cells. Cell 111:241-250 
73. Nusse R (2008) Wnt signaling and stem cell control. Cell Res 18:523-527

74. Niehrs C, Acebron SP (2012) Mitotic and mitogenic Wnt signalling. EMBO J 31:2705-2713

75. Wise DR, DeBerardinis RJ, Mancuso A, Sayed N, Zhang XY et al (2008) Myc regulates a transcriptional program that stimulates mitochondrial glutaminolysis and leads to glutamine addiction. Proc Natl Acad Sci USA 105:18782-18787

76. Dang CV (2010) Rethinking the Warburg effect with Myc micromanaging glutamine metabolism. Cancer Res 70:859-862

77. Kim JW, Gao P, Liu YC, Semenza GL, Dang CV (2007) Hypoxia-inducible factor 1 and dysregulated c-Myc cooperatively induce vascular endothelial growth factor and metabolic switches hexokinase 2 and pyruvate dehydrogenase kinase 1. Mol Cell Biol 27:7381-7393

78. Goldbeter A (1973) Patterns of spatiotemporal organization in an allosteric enzyme model. Proc Natl Acad Sci USA 70:3255-3259

79. Prigogine I, Nicolis G (1971) Biological order, structure and instabilities. Q Rev Biophys 4:107-148

80. Mor I, Cheung EC, Vousden KH (2011) Control of glycolysis through regulation of PFK1: old friends and recent additions. Cold Spring Harb Symp Quant Biol 76:211-216

81. Chocarro-Calvo A, Garcia-Martinez JM, Ardila-Gonzalez S, De la Vieja A, Garcia-Jimenez C (2013) Glucose-induced beta-catenin acetylation enhances Wnt signaling in cancer. Mol Cell 49:474-486

82. Aguilera O, Munoz-Sagastibelza M, Torrejon B, Borrero-Palacios A, Del Puerto-Nevado L et al (2016) Vitamin C uncouples the Warburg metabolic switch in KRAS mutant colon cancer. Oncotarget 7:47954-47965

83. Khatami M (2016) Is cancer a severe delayed hypersensitivity reaction and histamine a blueprint? Clin Transl Med 5:35

84. Bax BE, Bloxam DL (1997) Energy metabolism and glycolysis in human placental trophoblast cells during differentiation. Biochim Biophys Acta 1319:283-292

85. Feller AC, Schneider H, Schmidt D, Parwaresch MR (1985) Myofibroblast as a major cellular constituent of villous stroma in human placenta. Placenta 6:405-415

86. Chiavegato A, Bochaton-Piallat ML, D'Amore E, Sartore S, Gabbiani G (1995) Expression of myosin heavy chain isoforms in mammary epithelial cells and in myofibroblasts from different fibrotic settings during neoplasia. Virchows Arch 426:77-86

87. Matsumura S, Sakurai K, Shinomiya T, Fujitani N, Key K et al (2011) Biochemical and immunohistochemical characterization of the isoforms of myosin and actin in human placenta. Placenta 32:347-355

88. Lecarpentier Y, Claes V, Lecarpentier E, Guerin C, Hebert JL et al (2014) Ultraslow myosin molecular motors of placental contractile stem villi in humans. PLOS ONE 9:e108814

89. Lecarpentier Y, Claes V, Hebert JL, Krokidis X, Blanc FX et al (2015) Statistical mechanics of the human placenta: a stationary state of a near-equilibrium system in a linear regime. PLOS ONE 10:e0142471

90. Carthy JM, Garmaroudi FS, Luo Z, McManus BM (2011) Wnt3a induces myofibroblast differentiation by upregulating TGF-beta signaling through SMAD2 in a beta-catenin-dependent manner. PLOS ONE 6:e19809

91. Bernard K, Logsdon NJ, Ravi S, Xie N, Persons BP et al (2015) Metabolic reprogramming is required for myofibroblast contractility and differentiation. J Biol Chem 290:25427-25438

92. Polakis $P$ (2012) Drugging Wnt signalling in cancer. EMBO J 31:2737-2746

93. Polakis P (2012) Wnt signaling in cancer. Cold Spring Harb Perspect Biol. doi:10.1101/cshperspect.a008052

94. Fuchs $E$ (2009) The tortoise and the hair: slow-cycling cells in the stem cell race. Cell 137:811-819

95. Morin PJ, Sparks AB, Korinek V, Barker N, Clevers H et al (1997) Activation of beta-catenin-Tcf signaling in colon cancer by mutations in betacatenin or APC. Science 275:1787-1790

96. Najdi R, Holcombe RF, Waterman ML (2011) Wnt signaling and colon carcinogenesis: beyond APC. J Carcinog 10:5

97. Sarraf P, Mueller E, Smith WM, Wright HM, Kum JB et al (1999) Lossof-function mutations in PPAR gamma associated with human colon cancer. Mol Cell 3:799-804

98. Girnun GD, Smith WM, Drori S, Sarraf P, Mueller E et al (2002) APCdependent suppression of colon carcinogenesis by PPAR gamma. Proc Natl Acad Sci USA 99:13771-13776
99. Brockman JA, Gupta RA, Dubois RN (1998) Activation of PPAR gamma leads to inhibition of anchorage-independent growth of human colorectal cancer cells. Gastroenterology 115:1049-1055

100. Shimada T, Kojima K, Yoshiura K, Hiraishi H, Terano A (2002) Characteristics of the peroxisome proliferator activated receptor gamma (PPARgamma) ligand induced apoptosis in colon cancer cells. Gut 50:658-664

101. Osawa E, Nakajima A, Wada K, Ishimine S, Fujisawa N et al (2003) Peroxisome proliferator-activated receptor gamma ligands suppress colon carcinogenesis induced by azoxymethane in mice. Gastroenterology 124:361-367

102. Cesario RM, Stone J, Yen WC, Bissonnette RP, Lamph WW (2006) Differentiation and growth inhibition mediated via the RXR: PPAR gamma heterodimer in colon cancer. Cancer Lett 240:225-233

103. Sarraf P, Mueller E, Jones D, King FJ, DeAngelo DJ et al (1998) Differentiation and reversal of malignant changes in colon cancer through PPARgamma. Nat Med 4:1046-1052

104. Grommes C, Landreth GE, Heneka MT (2004) Antineoplastic effects of peroxisome proliferator-activated receptor gamma agonists. Lancet Oncol 5:419-429

105. McAlpine CA, Barak Y, Matise I, Cormier RT (2006) Intestinal-specific PPARgamma deficiency enhances tumorigenesis in ApcMin/+ mice. Int J Cancer 119:2339-2346

106. Mueller E, Sarraf P, Tontonoz P, Evans RM, Martin KJ et al (1998) Terminal differentiation of human breast cancer through PPAR gamma. Mol Cell 1:465-470

107. Clay CE, Namen AM, Atsumi G, Willingham MC, High KP et al (1999) Influence of J series prostaglandins on apoptosis and tumorigenesis of breast cancer cells. Carcinogenesis 20:1905-1911

108. Pignatelli M, Cocca C, Santos A, Perez-Castillo A (2003) Enhancement of BRCA1 gene expression by the peroxisome proliferator-activated receptor gamma in the MCF-7 breast cancer cell line. Oncogene 22:5446-5450

109. Elstner E, Muller C, Koshizuka K, Williamson EA, Park D et al (1998) Ligands for peroxisome proliferator-activated receptorgamma and retinoic acid receptor inhibit growth and induce apoptosis of human breast cancer cells in vitro and in BNX mice. Proc Natl Acad Sci USA 95:8806-8811

110. Inoue K, Kawahito Y, Tsubouchi Y, Kohno M, Yoshimura R et al (2001) Expression of peroxisome proliferator-activated receptor gamma in renal cell carcinoma and growth inhibition by its agonists. Biochem Biophys Res Commun 287:727-732

111. Guan YF, Zhang YH, Breyer RM, Davis L, Breyer MD (1999) Expression of peroxisome proliferator-activated receptor gamma (PPARgamma) in human transitional bladder cancer and its role in inducing cell death. Neoplasia 1:330-339

112. Lodillinsky C, Umerez MS, Jasnis MA, Casabe A, Sandes E et al (2006) Bacillus Calmette-Guerin induces the expression of peroxisome proliferator-activated receptor gamma in bladder cancer cells. Int J Mol Med 17:269-273

113. Radhakrishnan SK, Gartel AL (2005) The PPAR-gamma agonist pioglitazone post-transcriptionally induces p21 in PC3 prostate cancer but not in other cell lines. Cell Cycle 4:582-584

114. Mueller E, Smith M, Sarraf P, Kroll T, Aiyer A et al (2000) Effects of ligand activation of peroxisome proliferator-activated receptor gamma in human prostate cancer. Proc Natl Acad Sci USA 97:10990-10995

115. Yang FG, Zhang ZW, Xin DQ, Shi CJ, Wu JP et al (2005) Peroxisome proliferator-activated receptor gamma ligands induce cell cycle arrest and apoptosis in human renal carcinoma cell lines. Acta Pharmacol Sin 26:753-761

116. Tsubouchi Y, Sano H, Kawahito Y, Mukai S, Yamada R et al (2000) Inhibition of human lung cancer cell growth by the peroxisome proliferatoractivated receptor-gamma agonists through induction of apoptosis. Biochem Biophys Res Commun 270:400-405

117. Lee SY, Hur GY, Jung KH, Jung HC, Kim JH et al (2006) PPAR-gamma agonist increase gefitinib's antitumor activity through PTEN expression. Lung Cancer 51:297-301

118. Yao CJ, Lai GM, Chan CF, Cheng AL, Yang YY et al (2006) Dramatic synergistic anticancer effect of clinically achievable doses of lovastatin and troglitazone. Int J Cancer 118:773-779 
119. Sato H, Ishihara S, Kawashima K, Moriyama N, Suetsugu H et al (2000) Expression of peroxisome proliferator-activated receptor (PPAR)gamma in gastric cancer and inhibitory effects of PPARgamma agonists. $\mathrm{Br} J$ Cancer 83:1394-1400

120. Takahashi N, Okumura T, Motomura W, Fujimoto Y, Kawabata I et a (1999) Activation of PPARgamma inhibits cell growth and induces apoptosis in human gastric cancer cells. FEBS Lett 455:135-139

121. Lu J, Imamura K, Nomura S, Mafune K, Nakajima A et al (2005) Chemopreventive effect of peroxisome proliferator-activated receptor gamma on gastric carcinogenesis in mice. Cancer Res 65:4769-4774

122. Liao SY, Zeng ZR, Leung WK, Zhou SZ, Chen B et al (2006) Peroxisome proliferator-activated receptor-gamma Pro12Ala polymorphism, Helicobacter pylori infection and non-cardia gastric carcinoma in Chinese. Aliment Pharmacol Ther 23:289-294

123. Saez E, Tontonoz P, Nelson MC, Alvarez JG, Ming UT et al (1998) Activators of the nuclear receptor PPARgamma enhance colon polyp formation. Nat Med 4:1058-1061

124. Lefebvre AM, Chen I, Desreumaux P, Najib J, Fruchart JC et al (1998) Activation of the peroxisome proliferator-activated receptor gamma promotes the development of colon tumors in C57BL/6 J-APCMin/+ mice. Nat Med 4:1053-1057

125. Yang K, Fan KH, Lamprecht SA, Edelmann W, Kopelovich L et al (2005) Peroxisome proliferator-activated receptor gamma agonist troglitazone induces colon tumors in normal C57BL/6 J mice and enhances colonic carcinogenesis in Apc1638 N/+ Mlh1 \pm double mutant mice. Int J Cancer 116:495-499

126. Kulke MH, Demetri GD, Sharpless NE, Ryan DP, Shivdasani R et al (2002) A phase II study of troglitazone, an activator of the PPARgamma receptor, in patients with chemotherapy-resistant metastatic colorectal cancer. Cancer J 8:395-399

127. Venkata NG, Robinson JA, Cabot PJ, Davis B, Monteith GR et al (2006) Mono(2-ethylhexyl)phthalate and mono-n-butyl phthalate activation of peroxisome proliferator activated-receptors alpha and gamma in breast. Toxicol Lett 163:224-234

128. Saez E, Rosenfeld J, Livolsi A, Olson P, Lombardo E et al (2004) PPAR gamma signaling exacerbates mammary gland tumor development. Genes Dev 18:528-540

129. Cui Y, Miyoshi K, Claudio E, Siebenlist UK, Gonzalez FJ et al (2002) Loss of the peroxisome proliferation-activated receptor gamma (PPARgamma) does not affect mammary development and propensity for tumor formation but leads to reduced fertility. J Biol Chem 277:17830-17835

130. Papadaki I, Mylona E, Giannopoulou I, Markaki S, Keramopoulos A et a (2005) PPARgamma expression in breast cancer: clinical value and correlation with ERbeta. Histopathology 46:37-42

131. Burstein HJ, Demetri GD, Mueller E, Sarraf P, Spiegelman BM et al (2003) Use of the peroxisome proliferator-activated receptor (PPAR) gamma ligand troglitazone as treatment for refractory breast cancer: a phase II study. Breast Cancer Res Treat 79:391-397

132. Seargent JM, Yates EA, Gill JH (2004) GW9662, a potent antagonist of PPARgamma, inhibits growth of breast tumour cells and promotes the anticancer effects of the PPARgamma agonist rosiglitazone, independently of PPARgamma activation. Br J Pharmacol 143:933-937

133. Egerod FL, Nielsen HS, Iversen L, Thorup I, Storgaard T et al (2005) Biomarkers for early effects of carcinogenic dual-acting PPAR agonists in rat urinary bladder urothelium in vivo. Biomarkers 10:295-309

134. Yoshimura R, Matsuyama M, Segawa Y, Hase T, Mitsuhashi M et al (2003) Expression of peroxisome proliferator-activated receptors (PPARs) in human urinary bladder carcinoma and growth inhibition by its agonists. Int J Cancer 104:597-602

135. Lea MA, Sura M, Desbordes C (2004) Inhibition of cell proliferation by potential peroxisome proliferator-activated receptor (PPAR) gamma agonists and antagonists. Anticancer Res 24:2765-2771

136. Simons AL, Orcutt KP, Madsen JM, Scarbrough PM, Spitz DR (2012) Oxidative stress in cancer biology and therapy. In: Spitz DR, Dornfeld KJ, Krishnan J, Gius D (eds) Oxidative Stress in Applied Research and Clinical Practice. Humana Press, New York. doi:10.1007/978-1-61779-397-4

137. Alao JP (2007) The regulation of cyclin D1 degradation: roles in cancer development and the potential for therapeutic invention. Mol Cancer 6:24

138. Nicholson KM, Anderson NG (2002) The protein kinase B/Akt signalling pathway in human malignancy. Cell Signal 14:381-395
139. Manning BD, Cantley LC (2007) AKT/PKB signaling: navigating downstream. Cell 129:1261-1274

140. Karar J, Maity A (2011) PI3 K/AKT/mTOR pathway in angiogenesis. Front Mol Neurosci 4:51

141. Georgescu MM (2010) PTEN tumor suppressor network in PI3 K-Akt pathway control. Genes Cancer 1:1170-1177

142. Castellone MD, Teramoto H, Williams BO, Druey KM, Gutkind JS (2005) Prostaglandin E2 promotes colon cancer cell growth through a Gs-axinbeta-catenin signaling axis. Science 310:1504-1510

143. Shao J, Jung C, Liu C, Sheng H (2005) Prostaglandin E2 Stimulates the beta-catenin/T cell factor-dependent transcription in colon cancer. J Biol Chem 280:26565-26572

144. Ricchi P, Zarrilli R, Di Palma A, Acquaviva AM (2003) Nonsteroidal antiinflammatory drugs in colorectal cancer: from prevention to therapy. $\mathrm{Br}$ J Cancer 88:803-807

145. Goessling W, North TE, Loewer S, Lord AM, Lee S et al (2009) Genetic interaction of PGE2 and Wnt signaling regulates developmental specification of stem cells and regeneration. Cell 136:1136-1147

146. Li L, Kim HT, Nellore A, Patsoukis N, Petkova V et al (2014) Prostaglandin E2 promotes survival of naive UCB T cells via the Wnt/beta-catenin pathway and alters immune reconstitution after UCBT. Blood Cancer J 4:e178

147. Wong CT, Ahmad E, Li H, Crawford DA (2014) Prostaglandin E2 alters Wnt-dependent migration and proliferation in neuroectodermal stem cells: implications for autism spectrum disorders. Cell Commun Signal 12:19

148. Hazra S, Peebles KA, Sharma S, Mao JT, Dubinett SM (2008) The role of PPARgamma in the cyclooxygenase pathway in lung cancer. PPAR Res 2008:790568

149. Mendez M, LaPointe MC (2003) PPARgamma inhibition of cyclooxygenase-2, PGE2 synthase, and inducible nitric oxide synthase in cardiac myocytes. Hypertension 42:844-850

150. Savvidis C, Koutsilieris M (2012) Circadian rhythm disruption in cance biology. Mol Med 18:1249-1260

151. Goodwin BC (1965) Oscillatory behavior in enzymatic control processes. Adv Enzyme Regul 3:425-438

152. Hardin PE, Hall JC, Rosbash M (1990) Feedback of the drosophila period gene product on circadian cycling of its messenger RNA levels. Nature 343:536-540

153. Goldbeter A (2002) Computational approaches to cellular rhythms. Nature 420:238-245

154. Gekakis N, Staknis D, Nguyen HB, Davis FC, Wilsbacher LD et al (1998) Role of the CLOCK protein in the mammalian circadian mechanism. Science 280:1564-1569

155. Hogenesch JB, Gu YZ, Jain S, Bradfield CA (1998) The basic-helixloop-helix-PAS orphan MOP3 forms transcriptionally active complexes with circadian and hypoxia factors. Proc Natl Acad Sci USA 95:5474-5479

156. Schibler U, Sassone-Corsi P (2002) A web of circadian pacemakers. Cell 111:919-922

157. Reppert SM, Weaver DR (2002) Coordination of circadian timing in mammals. Nature 418:935-941

158. Sahar S, Sassone-Corsi P (2009) Metabolism and cancer: the circadian clock connection. Nat Rev Cancer 9:886-896

159. Wood PA, Yang X, Hrushesky WJ (2009) Clock genes and cancer. Integr Cancer Ther 8:303-308

160. Cao Y, Wang H, Ouyang Q, Tu Y (2015) The free energy cost of accurate biochemical oscillations. Nat Phys 11:772-778

161. Paschos GK, Ibrahim S, Song WL, Kunieda T, Grant G et al (2012) Obesity in mice with adipocyte-specific deletion of clock component Arntl. Nat Med 18:1768-1777

162. Yang X, Wood PA, Ansell CM, Ohmori M, Oh EY et al (2009) Beta-catenin induces beta-TrCP-mediated PER2 degradation altering circadian clock gene expression in intestinal mucosa of ApcMin/+ mice. J Biochem 145:289-297

163. Winter SL, Bosnoyan-Collins L, Pinnaduwage D, Andrulis IL (2007) Expression of the circadian clock genes Per1 and Per2 in sporadic and familial breast tumors. Neoplasia 9:797-800

164. Cao Q, Gery S, Dashti A, Yin D, Zhou Y et al (2009) A role for the clock gene per1 in prostate cancer. Cancer Res 69:7619-7625 
165. Suzuki T, Sato F, Kondo J, Liu Y, Kusumi T et al (2008) Period is involved in the proliferation of human pancreatic MIA-PaCa2 cancer cells by TNFalpha. Biomed Res 29:99-103

166. Mostafaie N, Kallay E, Sauerzapf E, Bonner E, Kriwanek S et al (2009) Correlated downregulation of estrogen receptor beta and the circadian clock gene Per1 in human colorectal cancer. Mol Carcinog 48:642-647

167. Yang MY, Yang WC, Lin PM, Hsu JF, Hsiao HH et al (2011) Altered expression of circadian clock genes in human chronic myeloid leukemia. J Biol Rhythms 26:136-148

168. Fujioka A, Takashima N, Shigeyoshi Y (2006) Circadian rhythm generation in a glioma cell line. Biochem Biophys Res Commun 346:169-174

169. Xia HC, Niu ZF, Ma H, Cao SZ, Hao SC et al (2010) Deregulated expression of the Per1 and Per2 in human gliomas. Can J Neurol Sci 37:365-370

170. Chen L, Yang G (2014) PPARs integrate the mammalian clock and energy metabolism. PPAR Res 2014:653017
171. Yang X, Downes M, Yu RT, Bookout AL, He W et al (2006) Nuclear receptor expression links the circadian clock to metabolism. Cell 126:801-810

172. Yang G, Jia Z, Aoyagi T, McClain D, Mortensen RM et al (2012) Systemic PPARgamma deletion impairs circadian rhythms of behavior and metabolism. PLoS ONE 7:e38117

173. Liu C, Li S, Liu T, Borjigin J, Lin JD (2007) Transcriptional coactivator PGC-1alpha integrates the mammalian clock and energy metabolism. Nature 447:477-481

174. Tan Z, Luo X, Xiao L, Tang M, Bode AM et al (2016) The role of PGC1alpha in cancer metabolism and its therapeutic implications. Mol Cancer Ther 15:774-782

175. Duez H, Staels B (2010) Nuclear receptors linking circadian rhythms and cardiometabolic control. Arterioscler Thromb Vasc Biol 30:1529-1534

\section{Submit your manuscript to a SpringerOpen ${ }^{\odot}$ journal and benefit from:}

- Convenient online submission

- Rigorous peer review

- Immediate publication on acceptance

- Open access: articles freely available online

- High visibility within the field

- Retaining the copyright to your article 